\section{AB0851 CLINICAL ASSOCIATIONS OF UVEITIS IN ASAS DEFINED AXIAL SPONDYLOARTHRITIS GROUP AND MODIFIED NEW YORK CRITERIA DEFINED ANKYLOSING SPONDYLITISGROUP}

C. Chiu Wai Shirley ${ }^{1 *}$, C.S. Lau ${ }^{2}$, H.H.L. Tsang ${ }^{1}$, O.M. Wong ${ }^{3}$, H.Y. Chung ${ }^{2}$. ${ }^{1}$ Medicine, QUEEN MARY HOSPITAL; ${ }^{2}$ Medicine, University of Hong Kong; ${ }^{3}$ Ophthalmology, Hong Kong Eye Hospital, Hong Kong, Hong Kong

Objectives: To identify and compare the associated factors for uveitis in Chinese patients with axial spondyloarthritis (SpA) and ankylosing spondylitis (AS). Methods: Patients fulfilling the Assessment of SpondyloArthritis (ASAS) axial $\mathrm{SpA}$ criteria were recruited consecutively from three rheumatology centres in Hong Kong. Clinical and biochemical parameters were collected. History of uveitis was enquired from both history and medical records. All patients received lumbosacral spine $\mathrm{x}$-rays, and whole spine and sacroiliac (SI) joint magnetic resonance imaging (MRI). MRIs were scored according to the Spondyloarthritis Research Consortium of Canada (SPARCC) scores. Patients were defined as axial SpA if they fulfilled the ASAS criteria, and AS if they fulfilled the modified New York $(\mathrm{mNY})$ criteria. Clinical and radiological findings were compared between patients with and without uveitis in the two groups. Factors associated with uveitis were identified with univariate analyses and multivariate logistic regression analyses. Results: Among 253 patients, 67 (26.5\%) patients had a history of uveitis. The male to female ratio was 55.7 to 44.3 . Disease duration was $12.3 \pm 11.7$ years. In the axial SpA group, univariate analyses showed that the following factors were associated with uveitis: back pain duration, age, HLA-B27 positivity, history of inflammatory bowel disease (IBD), tender joint count, Ankylosing Spondylitis Disease Activity Index (ASDAS) and SPARCC score of spine. Multivariate regression showed that older age (OR 1.05; $p=0.01$ ), HLA-B27 positivity (OR 11.79; $p=0.01$ ) and history of IBD (OR $9.74 ; p=0.04$ ) were positively associated with uveitis. In the AS group, univariate analyses showed that the following were associated with uveitis: back pain duration, age, male sex, HLA-B27 positivity, tender joint count, ASDAS, SPARCC score of spine and SPARCC score of SI joints. Multivariate regression showed that back pain duration ( $O R 1.05 ; p=0.01)$ and male sex (OR $3.46 ; p=0.03$ ) were associated with uveitis.

Conclusions: Clinical factors associated with uveitis are similar in the axial SpA and AS groups. The former group is associated more with IBD, and the latter with male sex.

Disclosure of Interest: None declared

DOI: 10.1136/annrheumdis-2018-eular.2370

\section{AB0852 GENDER DIFFERENCES IN AXIAL AND PERIPHERAL SPONDYLOARTHRITIS: RESULTS FROM THE ESPERANZA COHORT}

C. Urrego Laurín ${ }^{1}$, V. Navarro-Compán ${ }^{2}$, P. Zurita ${ }^{1}$, T. Ruiz Jimeno ${ }^{3}$, C. Campos fernandez ${ }^{4}$, J. Mulero Mendoza ${ }^{5}$, E. De Miguel Mendieta ${ }^{2}$, on behalf of ESPeranza Group. ${ }^{1}$ Hospital General de Segovia, Segovia; ${ }^{2}$ Hospital Universitario la Paz, IdiPaz, Madrid; ${ }^{3}$ Hospital Sierrallana. Torrelavega, Santander, ${ }^{4}$ Hospital Universitario de Valencia, Valencia; ${ }^{5}$ Hospital Universitario Puerta de Hierro, Madrid, Spain

Background: In patients with spondyloarthritis $(\mathrm{SpA})$, published data indicate different manifestations and outcomes between genders. Nevertheless, the evidence in patients with early and peripheral disease is lacking.

Objectives: To evaluate differences in the presentation of the disease between genders in patients with early axial and peripheral SpA (axSpA, pSpA).

Methods: This study was carried out within the framework of the ESPeranza program, which was a Spanish multicenter initiative aiming to facilitate early diagnosis and follow-up of patients with SpA between 2008-11. Out of 775 patients referred, 377 patients fulfilled the ASAS classification criteria for SpA:291(77\%) axSpA and 86 (23\%) pSpA. Demographic and disease characteristics were compared between genders using Chi-square (for categorical variables) and Student $t$ (for continuous variables) tests

Results: In total, 241 (64\%) patients were males (191 axSpA and $50 \mathrm{pSpA}$ ). In the axSpA group, males had more frequently radiographic sacroiliac damage, elevated CRP, HLA-B27 positive and morning stiffness, while females had higher values of ESR and more frequency of peripheral arthritis (table 1). Within the pSpA group, male gender was significantly associated with higher diagnostic delay, psoriasis and elevated CRP while women had higher rates of functional limitation and ESR values.

\begin{tabular}{|c|c|c|c|c|c|c|}
\hline \multirow[t]{2}{*}{ Characteristic } & \multicolumn{3}{|c|}{$\begin{array}{l}\text { Axial Spondylarthritis } \\
\text { (n: 291) }\end{array}$} & \multicolumn{3}{|c|}{$\begin{array}{l}\text { Periferical Spondylarthritis } \\
\text { (n:86) }\end{array}$} \\
\hline & $\begin{array}{c}\text { Males } \\
(n: 191)\end{array}$ & $\begin{array}{l}\text { Females } \\
(\mathrm{n}: 100)\end{array}$ & $\begin{array}{c}P \\
\text { value }\end{array}$ & $\begin{array}{l}\text { Males } \\
\text { (n: 50) }\end{array}$ & $\begin{array}{c}\text { Females } \\
(\mathrm{n}: 36)\end{array}$ & $\begin{array}{c}P \\
\text { value }\end{array}$ \\
\hline Age (yrs) & $31.6 \pm 7.1$ & $32.8 \pm 6.8$ & 0.2 & $33.1 \pm 8.4$ & $32.4 \pm 6.9$ & 0.7 \\
\hline Family history & $67(35.1)$ & $34(34.0)$ & 0.9 & $15(30.0)$ & $16(44.4)$ & 0.2 \\
\hline Symptoms dur (m) & $13.1 \pm 6.9$ & $12.7 \pm 6.4$ & 0.6 & $10.4 \pm 6.4$ & $7.7 \pm 5.5$ & 0.04 \\
\hline Morning stiffness & $138(72.3)$ & $60(60.0)$ & 0.03 & $3(6.0)$ & $3(8.3)$ & 0.7 \\
\hline IBP (ASAS criteria) & $74(38.7)$ & $38(38.0)$ & 0.9 & & & \\
\hline Arthritis & $42(22.0)$ & $11(11.0)$ & 0.02 & $48(96.0)$ & $35(97.2)$ & 0.8 \\
\hline Enthesitis & $38(19.9)$ & $19(19.0)$ & 0.9 & $28(56.0)$ & $15(41.7)$ & 0.2 \\
\hline Dactylitis & $13(6.8)$ & $3(3.0)$ & 0.2 & $17(34.0)$ & $11(30.6)$ & 0.7 \\
\hline Psoriasis & $23(12.0)$ & $10(10.0)$ & 0.6 & $21(42.0)$ & $7(19.4)$ & 0.03 \\
\hline IBD & $8(4.2)$ & $1(1.0)$ & 0.1 & $6(12.0)$ & $4(11.1)$ & 0.9 \\
\hline Uveitis & $11(5.8)$ & $12(12.0)$ & 0.06 & $1(2.0)$ & $0(0)$ & 0.4 \\
\hline HLA-B27+ & $151(79.1)$ & $68(68.0)$ & 0.03 & $16(32.0)$ & $12(33.3)$ & 1.0 \\
\hline CRP (mg/L) & $12.4 \pm 16.6$ & $7.8 \pm 11.7$ & 0.01 & $17.4 \pm 39.5$ & $8.6 \pm 11.5$ & 0.1 \\
\hline ESR (mmHg) & $12.3 \pm 13.9$ & $16.0 \pm 12.5$ & 0.04 & $11.9 \pm 14.1$ & $17.4 \pm 11.6$ & 0.09 \\
\hline $\operatorname{SJC}(0-68)$ & $0.3 \pm 1.6$ & $0.2 \pm 0.6$ & 0.2 & $1.4 \pm 2.4$ & $1.3 \pm 2.3$ & 0.8 \\
\hline VAS $(0-100)$ physician & $30 \pm 22$ & $28 \pm 22$ & 0.5 & $22 \pm 19$ & $27 \pm 25$ & 0.4 \\
\hline $\operatorname{VAS}(0-100)$ patient & $40 \pm 26$ & $45 \pm 29$ & 0.2 & $29 \pm 22$ & $35 \pm 29$ & 0.4 \\
\hline BASDAI $(0-10)$ & $3.7 \pm 2.2$ & $4.0 \pm 2.3$ & 0.3 & $3.2 \pm 2.1$ & $3.8 \pm 2.4$ & 0.2 \\
\hline BASFI $(0-10)$ & $2.2 \pm 2.3$ & $2.6 \pm 2.4$ & 0.2 & $1.3 \pm 1.4$ & $2.3 \pm 2.3$ & 0.04 \\
\hline BAMI $(0-10)$ & $1.4 \pm 1.3$ & $1.5 \pm 1.1$ & 0.4 & $1.2 \pm 1.1$ & $1.4 \pm 1.0$ & 0.5 \\
\hline MASES $(0-13)$ & $0.5 \pm 1.2$ & $0.5 \pm 1.5$ & 0.9 & $0.2 \pm 0.6$ & $0.2 \pm 0.4$ & 0.6 \\
\hline Sacroillitis-xRay (mNY) & $81(42.4)$ & $28(28.0)$ & 0.02 & & & \\
\hline Sacroilititis-MRI (ASAS) & $72(37.7)$ & $53(53.0)$ & 0.3 & & & \\
\hline Disability to work (\%) & $24(12.5)$ & $7(7.0)$ & 0.2 & $13(26.0)$ & $6(16.7)$ & 0.5 \\
\hline ASQoL (0-18) & $5.5 \pm 4.9$ & $6.6 \pm 4.5$ & 0.08 & $4.1 \pm 4.7$ & $4.9 \pm 5.3$ & 0.5 \\
\hline
\end{tabular}

Conclusions: In patients with $\mathrm{SpA}$, different disease manifestations between genders are observed already from the first stages of the disease. In patients with axSpA, males have worst prognostic factors compared with females. However, in $\mathrm{pSpA}$, females report poorer functionality despite being diagnosed earlier than male patients. This difference in phenotypes may be relevant when therapeutic decision-making.

Acknowledgements: Project ESPeranza was funded by Pfizer through the Spanish Foundation of Rheumatology (FER), is currently supported by a restricted grant from the of Instituto de Salud Carlos III (FIS PI13/02034) and Fondos FEDER.

Disclosure of Interest: None declared

DOI: 10.1136/annrheumdis-2018-eular.3992

\section{AB0853 1 THE ASSOCIATION OF VITAMIN D RESEPTOR LEVELS WITH DISEASE ACTIVITY PARAMETERS IN PATIENTS WITH ANKYLOSING SPONDYLITIS}

T. Kultur ${ }^{1}$, D. Öztaş ${ }^{2}$, D. Keskin ${ }^{1}$, G. Keskin ${ }^{3}$, A. İnal ${ }^{4}$, H. Kara ${ }^{5} .{ }^{1} P M R$, Kırıkkale University, Kırıkkale; ${ }^{2}$ Public Health, Yıldırım Beyazıt University; ${ }^{3}$ Immunology, Ankara University, Ankara; ${ }^{4}$ Immunology, Baskent University, Istanbul; ${ }^{5}$ Pharmacology, Yıldırım Beyazıt University, Ankara, Turkey

Background: Ankylosing Spondylitis (AS) is a chronic, systemic, inflammatory disease that involves sacroiliac, axial and peripheral joints with an unknown ethology. The role of vitamin D receptor (VDR) in the regulation of multiple pathophy siologic processes, like inflammation, infection and malignancies and systemic disease is not fully understood.

Objectives: The aim of this study, was to investigate the relationship between serum VDR levels and disease activity parameters in patients with AS.

Methods: Sixty-two patients with AS and 32 healthy volunteers were included into the study. Demographic features like age, duration of illness, medication, his tory of uveitis and peripheral involvement of the patients were recorded. Erythrocyte sedimentation rate (ESR), serum C-reactive protein (CRP) levels were recorded. The Bath AS Disease Activity Index (BASDAI) scores were calculated to determine disease activity. Serum Vitamin D receptor (VDR) level was measured by ELISA.

Results: There was no difference in Serum VDR levels between the patient and the control group ( $p=0.658$ ). In patients with active AS (BASDAI score $>4$ ) serum VDR level was significantly high $(p=0,000)$. Also serum VDR levels were statistically significantly high in patients with peripheral joint involvement and enthesis $(p=0,000$, non-steroidal anti inflammatory drugs (NSAID) compared to patients treated with biological agents $(p=0.00)$. Serum VDR levels were also significantly correlated with BASDAI, CRP and ESR in the patient group $(p=0.00, r=0,751$, $\mathrm{p}=0.00, r=0751 \mathrm{p}=0.00, r=0806$ respectively).

Conclusions: In our study, serum VDR levels are related with disease activity, clinical parameters, peripheral joint involvement and enthesis in patients with AS Our results suggest that serum VDR level may be used to predict disease activity and prognosis. Further studies in large cohorts are needed to determine the role of Serum VDR level in the pathophysiology of AS.

\section{REFERENCES}

[1] Cistromic and genetic evidence that the vitamin D receptor mediates sus ceptibility to latitude-dependent autoimmune diseases. Booth DR, Ding N 